\title{
Influence of border disease virus (BDV) on serological surveillance within the bovine virus diarrhea (BVD) eradication program in Switzerland
}

\author{
V. Kaiser ${ }^{1}$, L. Nebel ${ }^{1}$, G. Schüpbach-Regula ${ }^{2}$, R. G. Zanoni ${ }^{1^{*}}$ and M. Schweizer ${ }^{{ }^{*}}$ (D)
}

\begin{abstract}
Background: In 2008, a program to eradicate bovine virus diarrhea (BVD) in cattle in Switzerland was initiated. After targeted elimination of persistently infected animals that represent the main virus reservoir, the absence of BVD is surveilled serologically since 2012. In view of steadily decreasing pestivirus seroprevalence in the cattle population, the susceptibility for (re-) infection by border disease (BD) virus mainly from small ruminants increases. Due to serological cross-reactivity of pestiviruses, serological surveillance of BVD by ELISA does not distinguish between $B V D$ and BD virus as source of infection.

Results: In this work the cross-serum neutralisation test (SNT) procedure was adapted to the epidemiological situation in Switzerland by the use of three pestiviruses, i.e., strains representing the subgenotype BVDV-1a, BVDV-1h and BDSwiss-a, for adequate differentiation between BVDV and BDV. Thereby the BDV-seroprevalence in seropositive cattle in Switzerland was determined for the first time. Out of 1,555 seropositive blood samples taken from cattle in the frame of the surveillance program, a total of 104 samples (6.7\%) reacted with significantly higher titers against BDV than BVDV. These samples originated from 65 farms and encompassed 15 different cantons with the highest BDV-seroprevalence found in Central Switzerland. On the base of epidemiological information collected by questionnaire in case- and control farms, common housing of cattle and sheep was identified as the most significant risk factor for BDV infection in cattle by logistic regression.
\end{abstract}

Conclusion: This indicates that pestiviruses from sheep should be considered as a source of infection of domestic cattle and might well impede serological BVD surveillance.

Keywords: Bovine viral diarrhea virus (BVDV), Border disease virus (BDV), Pestivirus, Serum neutralisation test (SNT), Seroprevalence, Small ruminants, Cross-neutralisation, Eradication, Risk factor

\section{Background}

The genus Pestivirus in the family Flaviviridae comprises the four established species border disease virus (BDV), bovine viral diarrhea virus type-1 (BVDV-1), bovine viral diarrhea virus type-2 (BVDV-2) and classical swine fever virus (CSFV). Additional putative pestivirus species were isolated from giraffe ("Giraffe-1 pestivirus"),

\footnotetext{
* Correspondence: reto.zanoni@vetsuisse.unibe.ch;

matthias.schweizer@vetsuisse.unibe.ch

${ }^{1}$ Institute of Virology and Immunology, Federal Food Safety and Veterinary Office (FSVO) and Vetsuisse Faculty, University of Bern, Laenggass-Strasse 122, POB, CH-3001 Bern, Switzerland

Full list of author information is available at the end of the article
}

cattle ("atypical pestiviruses"), antelopes ("Pronghorn antelope pestivirus ") und piglets ("Bungowannah virus") [1-3]. Recently, an additional new strain termed "atypical porcine pestivirus" was isolated from pigs and piglets with congenital tremor $[4,5]$. The ruminant pestiviruses BVDV and BDV are important pathogens with a worldwide distribution [6] causing substantial economic losses in farm animal husbandry [7, 8].

Acute, transient infections of seronegative, immunocompetent animals with ruminant pestiviruses are frequently asymptomatic or are accompanied by mild respiratory or enteric symptoms $[9,10]$. By contrast, 
acute infection of pregnant cattle between approx. day 40 to 120 of gestation may cause transplacental transmission of non-cytopathogenic (ncp) biotypes to the fetus leading to the birth of persistently infected (PI) calves. These animals shed virus life-long and, thereby, comprise the primary pestivirus reservoir [11-13]. Similarly, lambs persistently infected with border disease virus caused by transplacental transmission display alterations in their fleece and show tremor (hence there are also called 'hairy shakers'), and they may succumb by a syndrome resembling Mucosal disease in cattle [14-17].

BDV in small ruminants occurs worldwide but with very variable seroprevalence depending, e.g., on the geographic location and the type of animal husbandry $[14,17-20]$. It was for the first time isolated in Switzerland in a flock of sheep that gave birth to lambs with generalized tremors and excessively hairy fleece in 2001 [21]. In a study published in 1995, seroprevalence in registered sheep flocks of breeding associations and in large flocks was around 20 and 65\%, respectively [22]. More recent data pointed to a slightly lower seroprevalence of $13.5 \%$ [23] or $16.1 \%$ [18] in sheep and $25.4 \%$ in goats [18]. In the latter study, it was demonstrated by means of cross-serum neutralisation tests (cross-SNT) that $9 \%$ of the sheep and $6 \%$ of the goats were infected with BDV. However, $31 \%$ and $66 \%$ of the seropositive sheep and goats, respectively, could not be assigned to BVDV or BDV leaving the source of infection unidentified.

Thus, even though broad serological cross-reactivity occurs among pestiviruses, considerable quantitative differences in neutralisation efficiency can be measured by SNT between different species (also called genotype) [24-26] and even subgenotypes [26-33]. To date, up to 21 ( $1 \mathrm{a}$ to $1 \mathrm{u})$ and three $(2 \mathrm{a}$ to $2 \mathrm{c})$ subgenotypes were described within the pestivirus species BVDV-1 and BVDV-2, respectively $[34,35]$, mostly based on comparison of the $5^{\prime}$-UTR (untranslated region) or $\mathrm{N}^{\text {pro }}$ (N-terminal protease) region of the pestiviral genomes. In Switzerland, BVDV-1e, $-1 \mathrm{~h},-1 \mathrm{k}$, and $-1 \mathrm{~b}$ are the most prevalent subgenotypes identified in cattle, while BVDV2 was never detected [30, 36, 37]. Similarly, BD viruses exhibit a large heterogeneity of strains [38] with 7 main subgenotypes and several atypical BDV strains described [39]. An additional phylogenetic group was detected in our institute exclusively in Switzerland and provisionally named BD Switzerland or BDSwiss [40, 41]. Lately, a similar isolate was identified in Italy and labeled as BDV-8 [42].

As ruminant pestiviruses are not strictly species specific, they are able to infect a variety of even-toed ungulates (Artiodactyla) [3, 13, 20]. Virus transmission was described between cattle and both, sheep and goats ([19, 43, 44], and references therein). Natural infections of cattle with BDV were reported in England and Wales [45, 46], Austria [47, 48], Italy [49] and New Zealand [50]. Common housing of cattle with persistently infected sheep was the most important cause for seroconversions, and resulted in reduced fertility and abortions in pregnant cows [19, 44, 46]. BDV-specific seroconversion in cattle was reported in Switzerland after pasturing them with BDV-positive sheep on common alpine meadows [51].

Based on the economic impact of BVDV infections in livestock, several European countries therefore initiated programs to eradicate BVDV in cattle $[52,53]$. In Switzerland, such a program was started in 2008 that particularly targeted on a nationwide identification and elimination of PI animals [54, 55]. Initially, $1.4 \%$ of all newborn calves were persistently infected with BVDV, which dropped to less than $0.02 \%$ by the end of 2012. From that time on, BVD control is based predominantly on risk-based serological surveillance of bulk milk and blood samples [56], with continuously decreasing seroprevalence. As serology performed by ELISA does not distinguish between an infection with BVDV from one with BDV, the impact of infection with BDV on serological surveillance on BVDV is not known. Thus, the aim of this study was to determine the frequency of BDV infections in cattle by using an optimized cross-neutralisation SNT, to identify potential risk factors for interspecies transmission with special emphasis on small ruminants, and to assess their possible influence on the serological surveillance of BVD in bovines.

\section{Methods}

Sera

Sera used in this study were from the period 2012 to 2014 and were initially rated as "indeterminate" or "positive" to antibodies $(\mathrm{Ab})$ against pestivirus by ELISA performed by a primary laboratory and later confirmed as positive by the national BVD reference laboratory (Institute of Veterinary Virology/Institute of Virology and Immunology, Bern, Switzerland). A serum was confirmed as positive when it was either positive in the institutes "in house"-ELISA [57] or when it was rated positive in a serum neutralisation test (SNT) using BVDV-1a (Table 1) as challenge virus. Sera were only included if they were obtained from animals that were at least 6 months old at the time of sampling and that were born later than Sept. 30, 2009, i.e., after phase 2 of the Swiss BVD eradication program [58]. If several samples from the same animal were obtained, only the one that was analysed first in the reference laboratory was used for the analysis. All sera were stored at $-20{ }^{\circ} \mathrm{C}$ prior to use. Overall, 1,568 sera fulfilled the criteria mentioned 
Table 1 Ruminant pestivirus isolates selected for SNT

\begin{tabular}{|c|c|c|c|c|c|}
\hline Pestivirus & Subgenotype & Isolate & Species & Source ${ }^{d}$ & Reference \\
\hline BDV & Swiss-a & R9336/11 & Cattle & IW/IVI BE & {$[40]$} \\
\hline BDV & Swiss-b & R4785/06/CH-BD4 & Sheep & IW/IVI BE & [44] \\
\hline BDV & 3 & R1343/01/CH-BD1 & Sheep & IW/IVI BE & [36] \\
\hline BDV & $1 a$ & Moredun & Sheep & P. Nettleton ${ }^{a}$ & [72] \\
\hline BVDV-1 & $1 \mathrm{~h}$ & $\mathrm{CH}-04-01 \mathrm{~b}$ & Cattle & IW/IVI BE & [30] \\
\hline BVDV-1 & le & CH-Maria & Cattle & IW/IVI BE & {$[30]$} \\
\hline BVDV-1 & $1 \mathrm{k}$ & CH-Suwa (ncp) ${ }^{c}$ & Cattle & IW/IVI BE & [30] \\
\hline BVDV-1 & $1 b$ & $\mathrm{CH}-04-05$ & Cattle & IW/IVI BE & [30] \\
\hline BVDV-1 & $1 a$ & $\mathrm{R} 1935 / 72(\mathrm{cp})^{\mathrm{c}}$ & Cattle & IW/IVI BE & [59] \\
\hline BVDV-2 & $2 a$ & 890 & Cattle & J. F. Ridpath ${ }^{\mathrm{b}}$ & [73] \\
\hline
\end{tabular}

${ }^{a}$ Moredun Research Institute, Edinburgh, Scotland

${ }^{b}$ National Animal Disease Center, Ames IA, USA

${ }^{c} c p$ cytopathogenic, $n c p$ non-cytopathogenic

${ }^{\mathrm{d}} \mathrm{IVV} / \mathrm{IVI} \mathrm{BE}=$ Institute of Veterinary Virology/Institute of Virology and Immunology, Bern

above, with 506, 536, and 526 sera obtained in the years 2012, 2013, and 2014, respectively.

\section{Cells}

Bovine turbinate (BT) cells were prepared at the Institute of Veterinary Virology (University of Bern, Switzerland) from bovine fetuses obtained from a local abattoir and were maintained in Earle's minimal essential medium (E-MEM; Biochrom GmbH, Berlin, Germany) supplemented with $15 \%$ fetal calf serum (FCS) (2\% during experiments), $100 \mathrm{U} / \mathrm{ml}$ penicillin, and $100 \mu \mathrm{g} / \mathrm{ml}$ streptomycin at $37{ }^{\circ} \mathrm{C}$ in a humidified $5 \% \mathrm{CO}_{2}$ atmosphere. FCS was free of pestivirus and antibodies to BVDV/BDV as tested by virus isolation and SNT, respectively. BT cells were found to be free of pestivirus by immunoperoxidase staining, and they were used to produce virus stocks, and to perform SNTs and virus (back-)titrations.

\section{Production of challenge viruses used for SNT}

Overall, 10 strains of ruminant pestiviruses from different subgenotypes were selected as challenge virus for the SNT $(4 \times$ BDV, $5 \times$ BVDV-1 and $1 \times$ BVDV -2$)$ (Table 1). All major subgenotypes hitherto isolated in Switzerland were represented by one isolate (BDSwiss-a, BDSwiss-b, BDV-3 and BVDV-1h, -1e, -1k, -1b) [37, 40]. With the exception of the North American strain Oregon C24 (R1935/72, BVDV-1a, [59]), all isolates were of the non-cytopathogenic (ncp) biotype. Each isolate was propagated in $150 \mathrm{~cm}^{2}$ cell culture flasks (TPP AG, Trasadingen, Switzerland) seeded with $3 \times 10^{6}$ BT cells in $50 \mathrm{ml} \mathrm{E-MEM}$ with $15 \%$ FCS. One day post-seeding, the cells were infected for $1 \mathrm{~h}$ at a multiplicity of infection (moi) of 0.01 in $10 \mathrm{ml}$ E-MEM with 7\% FCS followed by the addition of $40 \mathrm{ml}$ of E-MEM with $7 \%$ FCS. Cell infected with an ncp biotype of pestivirus were further incubated for 5 days at $37{ }^{\circ} \mathrm{C}$ and $5 \% \mathrm{CO}_{2}$, whereas the cells infected with the cytopathogenic (cp) BVDV-1a strain were harvested at the time when $80 \%$ of the cells showed signs of cytopathic effect (CPE) as judged by light microscopy. Virus stocks were obtained by freeze-thawing the cells at $-20{ }^{\circ} \mathrm{C}$ and removal of cell debris by centrifugation for $15 \mathrm{~min}$ at 10,000g ( $\mathrm{HiCen}^{\circ}$ 21C, Hemotec GmbH, Gelterkinden, Switzerland). Aliquots of $0.5 \mathrm{ml}$ were stored at $-80{ }^{\circ} \mathrm{C}$ until use.

\section{Homologous sera}

For each of the 10 subgenotypes, a serum as homologous as possible was chosen. Eight out of 10 sera were Swiss field sera, whereas the immune sera to the genotypes BVDV-1a (strain R1935/72) and BVDV-2 were obtained from vaccine trials in Switzerland and Germany, respectively. The latter was raised against the BVDV-2 strain CS8644 [60] and was kindly provided by G. Wolf (LMU, Munich, Germany). For the subgenotype BDV-1a that was never detected in Switzerland to date, no homologous serum was available and, thus, we used a field serum from an antibody-positive heifer with unknown source of infection that displayed a rather high titer against BDV-1a. All sera were stored at $-20{ }^{\circ} \mathrm{C}$.

\section{Serum neutralisation test}

For the detection and quantification of pestivirusspecific neutralising antibodies in cattle sera, a serum neutralisation test (SNT), which is considered the gold standard in BVDV serology [61, 62], was developed and optimized for the current situation in Switzerland. Basically, the SNT was done according to the directions of the OIE [63]. Briefly, sera to be tested were pre-diluted tenfold in E-MEM with 2\% FCS and inactivated for 30 min at $56{ }^{\circ} \mathrm{C}$. In the cases were only an insufficient amount of serum was available for all experiments, the serum was pre-diluted 20- $(n=46)$ or 40 -fold $(n=6)$. 
Thereafter, sera were further diluted seven times in twofold steps up to a dilution of 1 in 1,280. Dilutions were directly done in 96-well plates with 4 wells per dilution and in a volume of $50 \mu \mathrm{l}$ of serum per well. Afterwards, 100 tissue culture infectious dose $50 \quad\left(\mathrm{TCID}_{50}\right)$ of challenge virus in $50 \mu \mathrm{l} \mathrm{E-MEM} \mathrm{with} 2 \%$ FCS per well were added and the plates were incubated for one hour at $37{ }^{\circ} \mathrm{C}$ in a humidified $5 \% \mathrm{CO}_{2}$ atmosphere. Subsequently, a cell suspension in E-MEM with $2 \%$ FCS with 20,000 cells in a volume of $100 \mu \mathrm{l}$ was added to each well and further incubated for 4 to 5 days. For each experiment, a positive ( $\alpha$-BVDV-1b) and a negative control serum was included, and to control for possible serum cytotoxicity, $50 \mu \mathrm{l}$ of serum of the first pre-dilution was added to another well in the absence of challenge virus. For evaluation of the ncp strains, immunoperoxidase staining was performed, whereas the neutralisation of the $\mathrm{cp}$ strain was directly quantified by analysis of the CPE by light microscopy. The neutralisation titer was calculated according to Spearman-Kaerber and expressed as reciprocal value of the dilution required for $50 \%$ of the wells exhibiting neutralisation of the challenge virus. Samples with a titer greater than 8 were rated as positive.

In order to differentiate the source of infection, we performed cross-neutralisation tests using different strains of ruminant pestiviruses as challenge virus in parallel SNTs. To identify the strains with the best discriminatory power, we screened various combinations of BVDV and BDV as challenge virus, whereby an at least fourfold difference of their SNT titers were regarded as significant [63]. Taking the samples with low volume (20-fold pre-dilution) into account, sera with BVDV and BDV titers lower than 15 were regarded as negative. A ratio of the BVDV- and BDV-titer of lower than 4 was considered as "indeterminate".

\section{Virus titration}

Virus titrations were performed according to the direction of the OIE [63]. Briefly, the virus suspensions were diluted seven times in tenfold steps in E-MEM with 2\% FCS directly in 96-well plates with 6 wells per dilution using a volume of $50 \mu \mathrm{l}$ per well. Six wells were used as cell control with the simple addition of medium. After addition of the cell suspension $(20,000$ cells per well in $100 \mu \mathrm{l} \mathrm{E-}$ MEM with $2 \%$ FCS), the plates were incubated for 4 to 5 days at $37{ }^{\circ} \mathrm{C}$ in a humidified $5 \% \mathrm{CO}_{2}$ atmosphere. Virus titers were calculated according to Spearman-Kaerber and presented as tissue culture infectious dose 50 $\left(\mathrm{TCID}_{50}\right)$ per $\mathrm{ml}$. In every SNT, the amount of challenge virus applied $\left(100 \mathrm{TCID}_{50}\right)$ was controlled by back-titration in parallel to the $\mathrm{SNT}$, and a variation of half a log level was considered as acceptable $\left(10^{1.5}-10^{2.5}\right.$ TCID $_{50}=32$ to 316$)$ [63]. SNTs with the back-titration being outside of this range were repeated.

\section{Immunoperoxidase staining}

An immunoperoxidase staining was applied for cells infected with an ncp biotype of pestivirus. Cells were washed with PBS and subsequently thoroughly dried for at least one hour in the air flow of a safety cabinet. Thereafter, cells were fixed and permeabilised by incubation for two hours at $80{ }^{\circ} \mathrm{C}$. After the plates regained room temperature, the primary antibody (polyclonal swine- $\alpha$-BVDV hyperimmune serum prepared at the Institute of Veterinary Virology, University of Bern) was applied at a dilution of 1 to 750 in PBS with 5\% Tween20 (PBS-T) and incubated for $90 \mathrm{~min}$ at ambient temperature. After washing the cells three times with PBS-T, the secondary antibody (monoclonal peroxidaselabeled goat- $\alpha$-swine IgG; KPL, Gaithersburg, MD, USA) at a dilution of 1 to 1,000 in PBS-T with $5 \%$ low-fat powdered milk was applied for $90 \mathrm{~min}$ at room temperature. Subsequently, cells were washed twice with PBS-T and once with distilled water, followed by the addition of the substrate solution $(0.4 \mathrm{mg} / \mathrm{ml} 3$-Amino9-ethylcarbazole (AEC), 6\% dimethylformamide, 0.3\% $\mathrm{H}_{2} \mathrm{O}_{2}$ in $0.05 \mathrm{M}$ sodium acetate at $\mathrm{pH}$ 5.0) and incubation for approx. $30 \mathrm{~min}$ until an adequate staining was observed. Staining was stopped by washing the cells with distilled water.

\section{Case-control-study}

In order to detect risk factors for infection with border disease virus in livestock, we performed a retrospective case-control-study in farms whose young stock was surveyed serologically in the BVD eradication program in Switzerland and the Principality of Liechtenstein [64]. Young stocks are used for sero-surveillance in non-dairy herds. Each year, a random sample of one third of all farms that did not have a PI animal within the last 24 months, and all herds that either had a PI animal or a conspicuous result in bulk milk testing within this time period, are tested serologically. A group of young stock is tested that consists of 5 calves within a herd of an age of at least 6 months, which were born later than September 30, 2009 and more than one month after the removal of the last known PI animal from the farm. In addition, these calves should have stayed on a given farm for at least 6 months and not previously had a known contact with a PI animal. Based on these criteria, 54 farms with at least two seropositive animals in the time interval from February 2014 to June 2015 were selected as potential case farms. Sera from such potential case farms were tested in the cross-SNT, and the farm was considered a definite 
case farm if the herd contained at least one single seropositive animal that was rated as infected with BDV. Potential case farms which proved negative for BDV in the cross-SNT were excluded. Control farms were selected out of a pool of 10,753 farms (data collection by the Swiss Veterinary Service) that were never tested seropositive for BVDV since the start of the eradication program in 2008 and that had tested at least 5 animals as seronegative since the beginning of 2012. Control farms were selected using the Swiss animal movement database [56]. Because only 16 definitive case farms that also returned the questionnaire (see below) could be identified, the number of controls was increased to reach a relation of at least three controls per case.

\section{Data acquisition}

To identify potential risk factors for the occurrence of BDV infections in cattle, variables such as presence of small ruminants, herd size, use and distribution of breed, animal movement (summer pasturing), common housing and pasture management, and external contact to (wild) ruminants, were collected by a standardized, bipartite questionnaire for cattle farmers. The first part of the questionnaire contained a total of 55 questions regarding the farm itself, contacts to animals on neighboring farms, or purchase and sale (animal movement) with special emphasis on possible direct and indirect exposure to small ruminants. The second part mainly aimed at receiving information on the origin of seropositive and seronegative animals in case and control farms, respectively. Additionally, information on the breeds of the animals was obtained from the animal movement database. The questionnaires were issued in German, French and Italian, and were distributed to the Cantonal Veterinary Services starting in the middle of August 2014. Official veterinarians or the farm veterinarians were instructed by the Cantonal Veterinary Services to perform the interviews that were conducted on-site or by phone.

\section{Statistics}

Data of the SNTs and the questionnaires were entered into the spreadsheet Excel $^{\circ} 2010$ (Microsoft Corporation). The frequency distribution of the different potential risk factors in the 37 case and 280 control animals from 16 case and 56 control farms were statistically compared using the Chi-Square test for categorical variables and with the two-sample $t$-Test for normally distributed continuous variables, whereas the MannWhitney- $U$-Test was used for not normally distributed variables. After the univariable analysis of each individual risk factor according to the questionnaire, a multivariable logistic regression model with the potential risk factors $(p<0.1)$ was developed. In the model, clustering on the level of the farm was corrected with the GEE (generalized estimating equation) method [65]. None of the 13 identified potential risk factors were highly correlated with each other (correlation coefficient $<0.7$ ), therefore all of them were offered to the model. The final model was established by stepwise forward selection of the risk factors, until only significant factors $(p<0.05)$ and confounders remained in the model. Risk factors were considered as confounders and kept in the model if they altered the regression coefficient of another risk factor by more than $25 \%$. The univariable and multivariable statistical analysis of the data was performed with NCSS (version 9; NCSS LLC, Kaysville UT) and with PROC GENMOD in SAS (version 9.4; SAS Institute Inc., Cary NC), respectively. Model fit was assessed with QIC and QICu fit criteria, as well as with visual assessment of the residuals.

\section{Results \\ Distribution of field sera}

Around three quarters (74.8\%) of the 1,568 confirmed antibody-positive sera (see Methods section) were from cattle that were born prior to 2012 with $44 \%(n=512)$ thereof in the year 2010. Animals at the age of 6 to 11 months at the time of examination represented the largest age group $(n=347,22.1 \%)$ which is in accordance with the specifications of the «spot test» [55]. Overall, samples from 24 out of the 26 Swiss (half-) cantons and of the Principality of Liechtenstein were at our disposition, and the sample distribution was in good agreement (Fig. 1) with the cattle density per $\mathrm{km}^{2}$ per locality (based on postal code) in Switzerland.

\section{Cross-neutralisation of the selected BDV and BVD strains}

For the selection of the most appropriate $\mathrm{BD}$ and BVD virus strains to be used in the cross-SNT, we tested all possible combinations of the 10 isolates of ruminant pestiviruses (BDV, BVDV-1, BVDV-2; Table 1). For each subgenotype, we selected a serum as homologous as possible and titrated them in the SNT with all the pestivirus strains (see Additional file 1: Table S1). With only few exceptions, the highest titers were detected with the homologues pairs of virus and serum. The highest titer of 5,120 was observed with the anti-BVDV-1e serum and the corresponding virus strain $\mathrm{CH}$-Maria. The only exceptions were the sera raised against BDSwiss-a, BDV-1a, and BVDV-1k, which reacted equally or even stronger in response to other virus isolates than their homologous virus strain. As expected $[26,66]$, the anti-BVDV-2a serum exhibited a low (average titer $=48)$ and a medium (average titer $=135$ ) 


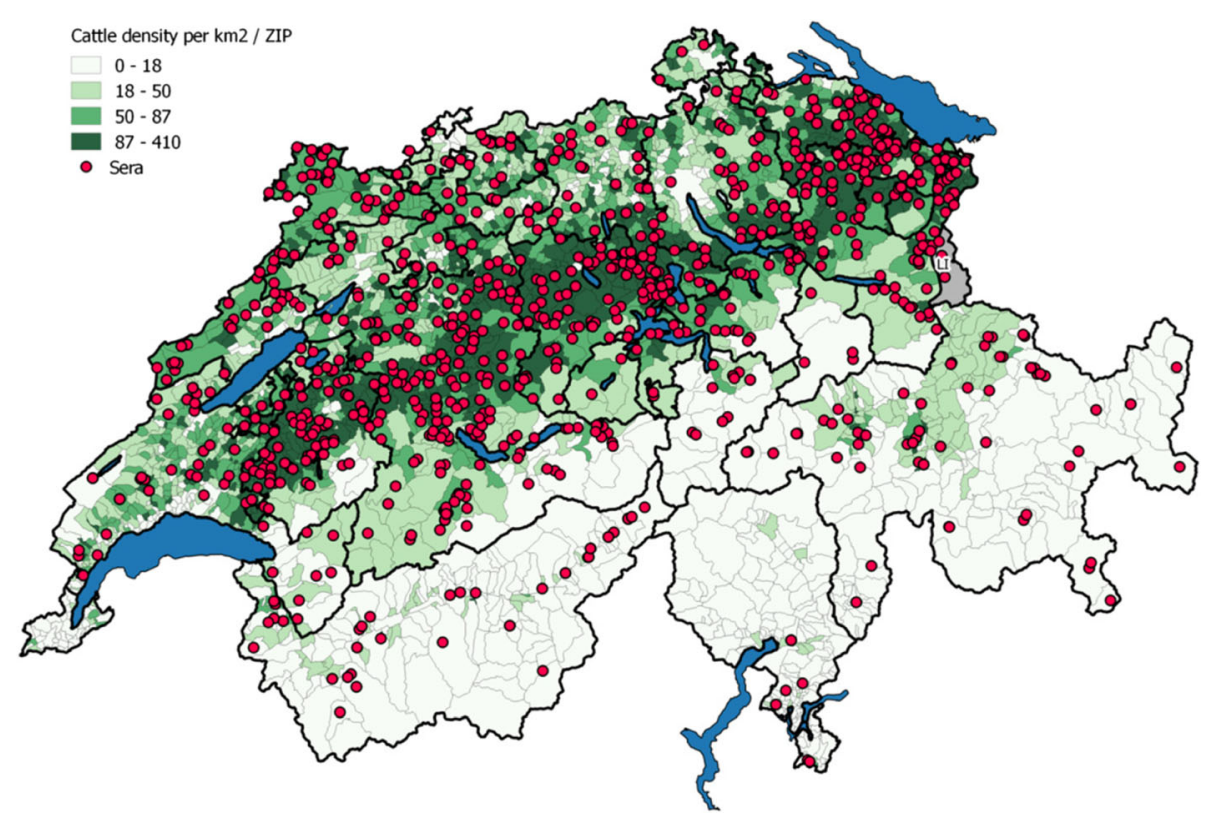

Fig. 1 Geographic distribution of field sera and density of the cattle population in Switzerland and of the Principality of Liechtenstein (LI). The map was created with the geographic information system QGIS 2.8.1-Wien. The number of cattle per ZIP (postal code; data 2014) were obtained from the Swiss Federal Statistical Office (https://www.pxweb.bfs.admin.ch); n (Farms providing sera) $=898$

neutralisation reactivity against BDV and BVDV-1, respectively. Conversely, the anti-BDV sera poorly (mean titer $=19$ ) and moderately (mean titer $=164$ ) neutralized the BVDV-2a strain 890 and the BVDV-1 strains, respectively. All BVDV-1 sera except the one directed against BVDV-1h only weakly neutralized BD viruses (mean titer $=47$ ), whereas their cross-neutralisation was rather high against heterologous BVDV-1 strains (mean titer $=523)$. Finally, sera directed against BDV showed a low and medium neutralisation activity towards BVDV-1 strains (mean titer $=57$ ) and heterologous BD viruses (mean titer $=192$ ), respectively.

\section{Coefficients of antigenic similarity (R)}

The antigenic relatedness of a pair of viruses was determined by calculating the coefficient of antigenic similarity (R) [67] according to the following formula:

$$
\begin{aligned}
R & =100 \\
& \times \sqrt{\frac{\text { titer virus isolate } A \text { with serum } B \times \text { titer virus isolate } B \text { with serum } A}{\text { titer virus isolate } A \text { with serum } A \times \text { titer virus isolate } B \text { with serum } B}}
\end{aligned}
$$

A value of $R \leq 25$ is considered to denote a significant antigenic difference between the virus strains [24, 30]. All possible combinations of $\mathrm{BD}$ and BVD viruses displayed an $R$-value lower than 25 , which is indicative of a significant antigenic difference between two strains. The largest differences with $R$-values lower than two were observed between BDV and BVDV-1 strains, whereas the four strains of BDV displayed the highest $R$ - values among each other (Table 2) with no significant difference between any two strains.

\section{Selection of the pestivirus strains used in cross- neutralisation of field sera}

The quotients of titers of the cross-neutralisation assays of the 10 sera with the four BD and the six BVD viruses were calculated for all possible pairwise combinations (Table 3), with the absolute numbers of the $\mathrm{SN}$ titers listed in supplementary Additional file 1: Table S1. Values of the quotient below 4 were considered as indeterminate. All antisera against BDV were correctly assigned with 4 different combinations of virus pairs (BVDV-1a and BDSwiss-a; BVDV-2a and BDSwiss-a or BDSwiss-b; BVDV-1k and BDSwiss-a). The six BVDV antisera were correctly classified in three pairwise combinations of the subgenotype BVDV-1h, e.g., with the strains BDSwiss-a, BDSwiss-b and BDV-3. Overall, the virus pair BVDV-1a and BDSwiss-a displayed the best differentiation of all sera, with correct classification of 8 out of 10 sera in the cross-neutralisation assays. By adding the results of the BVDV-1h strain CH-04-01b in combination with the BDV strain Swiss-a, both remaining BVDantisera (anti-BVDV-1h and anti-BVDV-2) could be properly assigned. Therefore, the pestivirus strains BVDV-1a, BVDV-1h and BDSwiss-a were selected as being optimally suited for the differentiation between BVDV and BDV as source of infection in the current epidemiological situation in Switzerland. 
Table 2 Coefficients of antigenic similarity (R) between BDV and BVDV isolates

\begin{tabular}{|c|c|c|c|c|c|c|c|c|c|c|}
\hline BDV \& BVDV isolates & BDV Swiss-a & BDV Swiss-b & $B D V-3$ & BDV-1a & BVDV-1h & BVDV-1e & BVDV-1k & BVDV-1b & BVDV-1a & BVDV -22 \\
\hline BDSwiss-a & 100 & 77.1 & 40.3 & 71.0 & 19.2 & $\leq 2.3$ & $\leq 13.6$ & 6.0 & $\leq 2.2$ & 4.8 \\
\hline BDSwiss-b & & 100 & 29.8 & 73.8 & 10.1 & 1.8 & 19.2 & 5.5 & 1.6 & 3.0 \\
\hline BDV-3 & & & 100 & 59.5 & 14.8 & 3.7 & 15.6 & 5.5 & 3.0 & 3.4 \\
\hline BDV-1a & & & & 100 & 20.1 & 4.8 & $\leq 23.8$ & 12.0 & 2.5 & 6.7 \\
\hline BVDV-1h & & & & & 100 & 13.6 & 52.3 & 32.4 & 12.5 & 11.5 \\
\hline BVDV-1e & & & & & & 100 & 22.9 & 13.1 & 7.1 & 6.5 \\
\hline BVDV-1k & & & & & & & 100 & 52.3 & 28.5 & 11.5 \\
\hline BVDV-1b & & & & & & & & 100 & 21.0 & 5.0 \\
\hline BVDV-1a & & & & & & & & & 100 & 3.6 \\
\hline BVDV-2a & & & & & & & & & & 100 \\
\hline
\end{tabular}

$R$-Values $\leq 25$ indicate significant antigenic differences between two isolates (in italics). For nondescript titers ( $\leq 14$ ), the value of 14 was taken for calculation and, accordingly, the $R$-values are marked with " $\leq$ "

Table 3 Ratios of the cross-SNT titers of 10 sera tested with all combinations of BDV and BVDV isolates

\begin{tabular}{|c|c|c|c|c|c|c|c|c|c|c|c|c|}
\hline \multirow[t]{3}{*}{ Sera } & \multicolumn{12}{|l|}{ Virus pair } \\
\hline & \multicolumn{4}{|l|}{ BVDV-1h } & \multicolumn{4}{|l|}{ BVDV-1e } & \multicolumn{4}{|l|}{ BVDV-1k } \\
\hline & BD Swiss-a & BD Swiss-b & BDV-3 & BDV-1a & BD Swiss-a & BD Swiss-b & BDV-3 & BDV-1a & BD Swiss-a & BD Swiss-b & BDV-3 & BDV-1a \\
\hline a-BDSwiss-a & 4.4 & 4.4 & 1.9 & 2.0 & 5.1 & 5.1 & 2.2 & 2.4 & 8.8 & 8.8 & 3.7 & 4.1 \\
\hline$a-B D S w i s s-b$ & $4.0^{a}$ & 6.7 & 1.8 & 2.2 & 5.6 & 9.5 & 2.6 & 3.1 & 8.8 & 14.7 & 4.0 & 4.8 \\
\hline a-BDV-3 & 1.1 & 0.9 & 2.8 & 0.9 & 1.5 & 1.3 & 4.0 & 1.3 & 4.4 & 3.7 & 11.4 & 3.7 \\
\hline a-BDV-1a & 1.7 & 2.6 & 1.7 & 1.5 & 3.1 & 4.8 & 3.1 & 2.8 & 11.4 & 17.6 & 11.4 & 10.5 \\
\hline a-BVDV-1h & 6.2 & 14.7 & 16.0 & 16.0 & 0.6 & 1.5 & 1.7 & 1.7 & 0.5 & 1.1 & 1.2 & 1.2 \\
\hline a-BVDV-1e & 64.6 & 60.3 & 32.3 & 26.6 & 365.7 & 341.3 & 182.9 & 150.6 & 11.4 & 10.7 & 5.7 & 4.7 \\
\hline $\mathrm{a}-B V D V-1 \mathrm{k}$ & 22.7 & 6.8 & 13.3 & 6.2 & 10.4 & 3.1 & 6.1 & 2.8 & 6.2 & 1.8 & 3.6 & 1.7 \\
\hline$a-B V D V-1 b$ & 22.7 & 19.0 & 26.7 & 16.0 & 10.4 & 8.7 & 12.2 & 7.3 & 4.8 & 4.0 & 5.6 & 3.4 \\
\hline a-BVDV-1a & 38.1 & 10.4 & 15.9 & 24.5 & 17.5 & 4.8 & 7.3 & 11.3 & 19.1 & 5.2 & 7.9 & 12.3 \\
\hline a-BVDV-2a & 8.0 & 4.3 & 8.0 & 3.4 & 7.3 & $4.0^{\mathrm{a}}$ & 7.3 & 3.1 & 1.7 & 0.9 & 1.7 & 0.7 \\
\hline \multirow[t]{3}{*}{ Sera } & \multicolumn{12}{|l|}{ Virus pair } \\
\hline & \multicolumn{4}{|l|}{ BVDV-1b } & \multicolumn{4}{|l|}{ BVDV-1a } & \multicolumn{4}{|l|}{ BVDV-2a } \\
\hline & BD Swiss-a & BD Swiss-b & BDV-3 & $\overline{B D V-1 a}$ & BD Swiss-a & BD Swiss-b & BDV-3 & $\overline{B D V-1 a}$ & BD Swiss-a & BD Swiss-b & BDV-3 & BDV-1a \\
\hline a-BDSwiss-a & 5.1 & 5.1 & 2.2 & 2.4 & 8.8 & 8.8 & 3.7 & 4.1 & 8.2 & 8.2 & 3.5 & 3.8 \\
\hline$a-B D S w i s s-b$ & 4.3 & 7.3 & 2.0 & 2.4 & 34.5 & 58.1 & 15.8 & 18.8 & 22.6 & 38.0 & 10.3 & 12.3 \\
\hline$a-B D V-3$ & 2.0 & 1.7 & 5.2 & 1.7 & 4.4 & 3.7 & 11.4 & 3.7 & 6.2 & 5.2 & 16.0 & 5.2 \\
\hline a-BDV-1a & 2.0 & 3.1 & 2.0 & 1.8 & 11.4 & 17.6 & 11.4 & 10.5 & 10.7 & 16.5 & 10.7 & 9.8 \\
\hline a-BVDV-1h & 1.5 & 3.7 & 4.0 & 4.0 & 0.6 & 1.4 & 1.5 & 1.5 & 0.5 & 1.3 & 1.4 & 1.4 \\
\hline a-BVDV-1e & 32.4 & 30.2 & 16.2 & 13.3 & 24.9 & 23.3 & 12.5 & 10.3 & 11.4 & 10.7 & 5.7 & 4.7 \\
\hline a-BVDV-1k & 19.1 & 5.7 & 11.2 & 5.2 & 6.2 & 1.8 & 3.6 & 1.7 & 2.6 & 0.8 & 1.5 & 0.7 \\
\hline$a-B V D V-1 b$ & 54.0 & 45.3 & 63.5 & 38.1 & 8.0 & 6.7 & 9.4 & 5.7 & 3.7 & 3.1 & 4.3 & 2.6 \\
\hline a-BVDV-1a & 69.8 & 19.1 & 29.1 & 45.0 & 234.8 & 64.3 & 97.8 & 151.5 & 5.7 & 1.5 & 2.4 & 3.6 \\
\hline a-BVDV-2a & 2.0 & 1.1 & 2.0 & 0.8 & 2.8 & 1.5 & 2.8 & 1.2 & 53.5 & 29.1 & 53.5 & 22.7 \\
\hline
\end{tabular}

For the calculation of the ratios of the $\mathrm{a}-\mathrm{BD}$ sera, the titer of BDV was taken as numerator and the titer of BVDV as denominator. For the calculation of the ratios of the a-BVD sera the reverse ratio was used. Ratios $<4$ are highlighted in bold

${ }^{\mathrm{a}}$ The exact value was slightly below 4.0 


\section{Neutralisation and cross-neutralisation of field sera}

In order to differentiate BVDV and BDV as source of infection, we employed the cross-SNT with the three challenge strains BVDV-1a, BVDV-1h, and BDSwiss-a as described above. From 1,568 samples that were initially confirmed to be positive for pestivirus antibodies and that originated from 898 farms, we were able to analyze 1,555 in the cross-SNT. This includes the six results to the BVDV-1a strain from the initial SNT that was applied by the reference laboratory for samples where not sufficient material was available to perform full cross-neutralisation.

Both, the average titer (geometric mean titer (GMT) = 346.3; median $=495.5$ ) of the field sera and the neutralisation titer of the majority of the individual samples (1,394 out of 1,549 samples) were higher towards the BVDV-1h isolate than the ones towards the BVDV-1a strain $\quad(G M T=125.5 ; \quad$ median $=135)$. The average $($ GMT $=74.8$; median $=80)$ as well as most of the single titers to BDSwiss-a were clearly lower than the values to the BVD viruses (Fig. 2a). The highest titer $(\geq 1,810)$ was reached with 153,14 , and one sera against BVDV-1h, BVDV-1a, and BDV, respectively. Most sera with negative neutralisation titers $(\leq 8)$ were observed using BDV in the SNT $(n=257)$.

\section{Identification of the source of infection by cross-SNT}

By combining the results of the SNTs with the virus strains of the subgenotype BVDV-1a and BDSwiss-a, we were able to differentiate the source of infection between BVDV and BDV in 550 out of 1,555 samples (35.4\%). By adding the BVD/BD-quotient with the BVDV-1h strain to the remaining samples (i.e., 870 samples that could not be assigned using only the BVDV-1a strain, and to 135 samples that were rated as negative), further 666 sera could be sourced to an infection with BVDV (Table 4). In 93\% of all BVD-positive cases, the sera had a higher titer towards BVDV-1h than BVDV-1a. Conversely, for samples that were assigned to an infection with BDV, their low reactivity towards the BVDV-1a strain was pivotal for their differentiation from BVDV (Fig. 2b). In no instance a contradictory combination of the results was observed. Overall, the majority of samples were assigned to BVD $(n=1,112,71.5 \%$; CI 95\%: 69.2-73.7\%), and only 104 cattle sera (6.7\%; CI 95\%: 5.5-8.0\%) were attributed to an infection with BDV. In 28 samples that could initially not be differentiated because they still exhibit full neutralisation even at the highest dilution, repetition of the experiments with more dilutions steps allowed their differentiation to an infection with $\operatorname{BVDV}(n=27)$ or $\operatorname{BDV}(n=1)$. The remaining sera could either not be differentiated $(n=286,18.4 \%$; CI 95\%: 16.5-20.4\%) or were regarded as negative $(n=53,3.4 \%$; CI 95\% 2.6-4.4\%) based on their low titers (titers $\leq 14$ ).

BDV as source of infection: distribution of samples

The 104 cattle sera that were assigned to BDV as source of infection originated from 65 farms within 15 cantons (Fig. 3). A large part of the samples came from Central Switzerland $(n=36)$, in accordance with the observation that the two cantons with the highest prevalence of
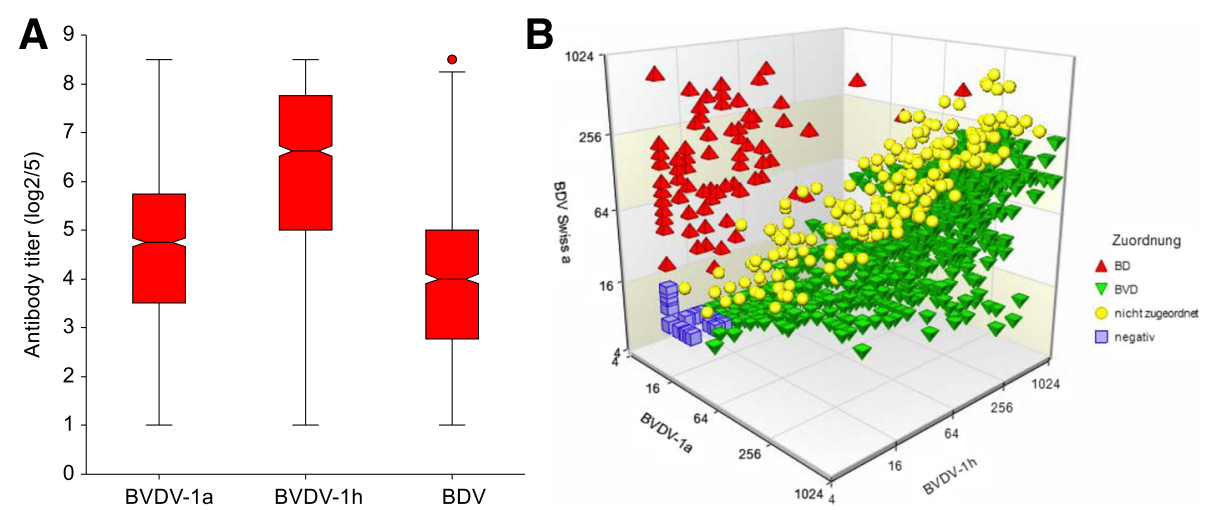

Fig. 2 Distribution of SNT titers of sera against BVDV-1a, BVDV-1h and BDV. a The box plots of titers of positive sera were created with the statistical software NCSS 9. Only positive titers ( $>8$ ) were included ( $n_{\text {BVDV-1a }}=1,400 ; n_{B V D V-1 h}=1,496 ; n_{B D V}=1,292$ ). For titers with a value of $\leq 14$ (20-fold pre-dilution), $\leq 28$ (40-fold pre-dilution) and $\geq 1,810$, the values 14, 28 and 1,810 were taken for calculation, respectively. The SNT titers are represented in the $y$-axis as logarithm to the base 2 including the standard 5 -fold pre-dilution, i.e., multiplication with 5 yields the final titer. b The scatter plot of the sera samples $(n=1,555)$ based on their titers against BDSwiss-a, BVDV-1a and BVDV-1h was created with the statistical software NCSS 9. The black dotted line represents the threefold rotational axis on which each of the three titers per sample would have the same value and, therefore, no assignment to "BVD" or "BD" is possible (yellow). BDV-specific sera with low reaction against BVDV-1a are located in the upper left section of the cube (red), whereas BVDV-specific sera with high reaction against BVDV-1h are located in the lower right section of the cube (green). Negative sera are in the lower left corner (purple) 
Table 4 Combinations of results from the cross-SNT tested with 3 isolates

\begin{tabular}{|c|c|c|c|c|c|c|}
\hline Evaluation with BVDV-1a \& BDV & & Evaluation with BVDV-1h \& BDV & Assignment $^{a}$ & $n=$ & $\begin{array}{l}\text { Percentage of combination } \\
\text { per assignment [\%] }\end{array}$ & Proportion overall [\%] \\
\hline BVD & \& & BVD & BVD & 428 & 38.5 & 71.5 \\
\hline BVD & $\&$ & Negative & & 4 & 0.4 & \\
\hline BVD & $\&$ & Indeterminate & & 13 & 1.2 & \\
\hline Indeterminate & \& & BVD & & 594 & 53.5 & \\
\hline Negative & \& & BVD & & 72 & 6.5 & \\
\hline BVD & & n.d. ${ }^{b}$ & & 1 & 0.1 & \\
\hline $\mathrm{BD}$ & $\&$ & $\mathrm{BD}$ & BD & 68 & 65.4 & 6.7 \\
\hline BD & $\&$ & Indeterminate & & 32 & 30.8 & \\
\hline BD & & n.d. ${ }^{b}$ & & 1 & 3.8 & \\
\hline Indeterminate & $\&$ & Indeterminate & Indeterminate & 276 & 96.5 & 18.4 \\
\hline Negative & \& & Indeterminate & & 10 & 3.5 & \\
\hline Negative & $\&$ & Negative & Negative & 52 & 98.1 & 3.4 \\
\hline Negative & & n.d. ${ }^{b}$ & & 1 & 1.9 & \\
\hline Total & & & & 1,555 & & 100 \\
\hline
\end{tabular}

"Sera with a ratio of $\geq 4$ were assigned as "BVD" or "BD", sera with a ratio $<4$ were "indeterminate", and sera with both titers $<15$ are "negative"

${ }^{b}$ n.d not done, due to insufficient amount of material

BDV-reactive sera (64.7 and 32.4\%) were from this area. Notably, in three of these farms in Central Switzerland, calves that were persistently infected with BDV were detected within the scope of the Swiss BVD eradication program (H.P. Stalder, personal communication and [37]). In 9 cantons and in the Principality of Liechtenstein, we could not detect any BDV positive sample within the 206 sera that we analyzed.
In 21 out of 29 farms where a BDV-specific sample and more than one positive serum in the cross-SNT was obtained, all of the samples were specific for BDV as source of infection. From the remaining farms, four had samples that could not be differentiated or were negative, whereas in the other four, BVDV could also be identified as source, sometimes in combination with indeterminate samples.

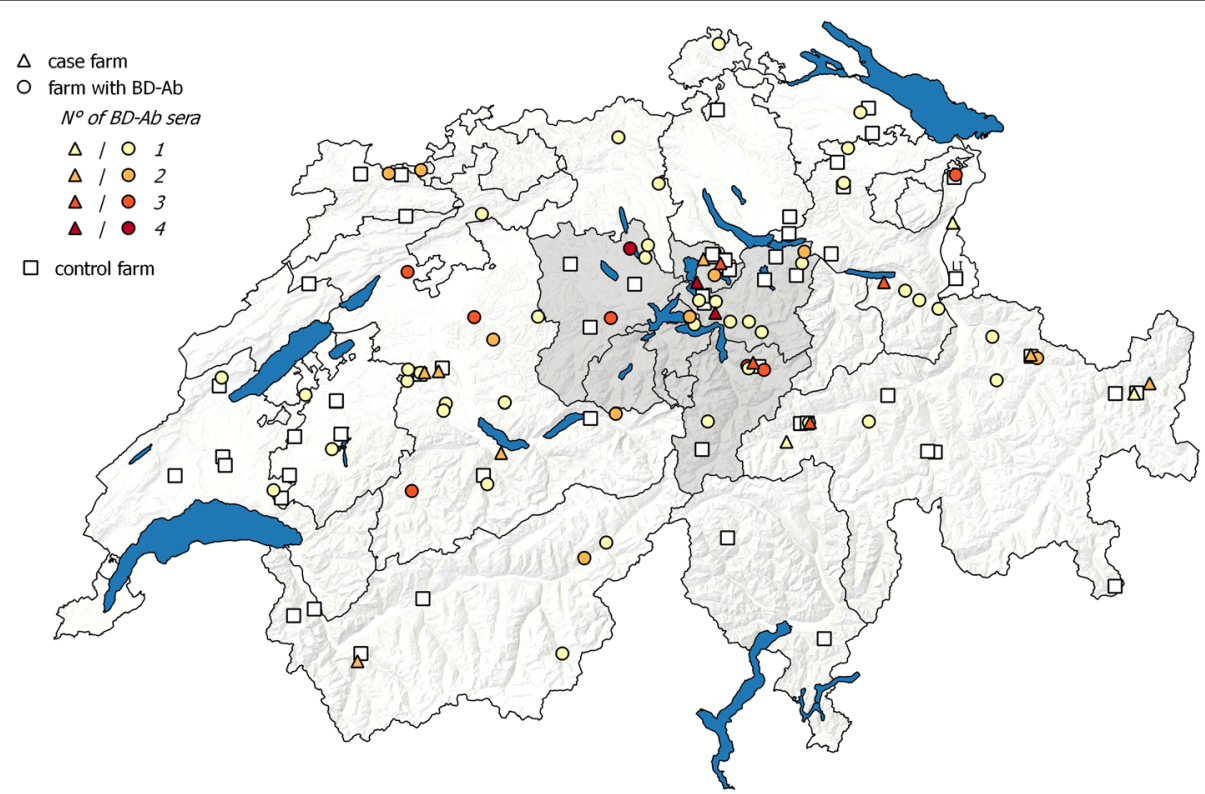

Fig. 3 Farms with BDV-positive sera and case and control farms in Switzerland and the Principality of Liechtenstein (LI). The location of farms with BDV-positive sera (circles) including the definitive case farms (triangle) and the control farms (squares) are presented. The number of BDV-specific sera from one to four is displayed by a color gradient from yellow to red as indicated in the figure 
According to information retrieved from the Swiss animal movement database [58], small ruminants were present on 44 farms (68\%) where BDV was identified as source of infection in at least one sample. Thereof, 27 (61\%) of these farms housed sheep, 4 (9\%) goats, and 13 (30\%) both, sheep and goats. By contrast, only a third of the farms without BDVpositive samples $(n=259,31 \%)$ kept small ruminants according to information obtained from the animal movement database.

\section{Selection of farms for the case-control-study}

We obtained detailed data on 54 potential case farms that were recruited between February 2014 and June 2015 based on the serological screening results using a standardized questionnaire. BDV was later identified by means of cross-SNT as the source of infection in 37 samples from 16 farms that were distributed across 7 cantons and the Principality of Liechtenstein (Fig. 3). Additional 3 samples from these definitive case farms were indeterminate and one was negative. In no case farm could we detect any BVDV-specific serum.

\section{Descriptive, univariable statistics}

By means of Pearsons's chi square test, we identified significant differences $(p<0.1)$ in 9 out of 50 categorical variables and, using Mann-Whitney- $U$-test or $t$-test, in 4 out of 5 continuous variables (Additional file 2: Table S2a and S2b). The variables sheep farming, sheep breed, and origin of cattle display the lowest $p$ values $(p<0.0001)$. Within the continuous variables, the number of cattle was considerably $(p=0.0006)$ and the number of sheep, goats, and loss of lambs was fairly different $(p=0.1)$ between the case and control groups (Additional file 3: Table S3).

\section{Logistic regression}

Variables that were significant according to the univariable analysis and additional variables of epidemiological relevance regarding animal movement (purchase, provenance) were introduced into the model of logistic regression by stepwise forward selection. At the farm level, the risk factors "same stable" (sheep and cattle are kept in the same stable; OR (odds ratio) $=167.23, \mathrm{CI}_{95 \%}$ : 15.37-1,819.29, $p<0.0001$ ) and "cattle purchase" (purchase of cattle within the last 12 months; $\mathrm{OR}=9.57$, $\mathrm{CI}_{95 \%}: 1.08-84.95 ; p=0.0426$ ), and at the level of the individual animal, the risk factor "cattle provenance" (cattle was purchased; $\mathrm{OR}=4.16, \mathrm{CI}_{95 \%}: 1.64-10.60 ; p=0.0028$ ) could be confirmed as significant in the final model.

\section{Discussion}

In this study, we investigated the frequency of BDV infections in cattle and evaluated their possible influence on the serological surveillance in the Swiss BVD eradication program. Thus, we selected one strain out of each major subgenotype of ruminant pestiviruses detected in Switzerland so far [37] in addition to the two strains previously used for differentiation in routine diagnostic, i.e., R1935/72 (BVDV-1a) and Moredun (BDV-1a). In order to choose the most appropriate challenge viruses in the cross-SNT to differentiate BVDV from BDV infections, all possible pairwise combinations out of the $6 \mathrm{BVDV}$ and $4 \mathrm{BDV}$ strains were tested (Table 1) together with sera that were as homologous as possible to the corresponding virus isolates. The combination of BVDV-1a and BDSwiss-a turned out to be an optimal combination that correctly assigned 8 out of 10 test sera (Table 3), including all BDV-specific samples, and that yielded the highest ratios of the neutralisation titers (mean $=33.6$ ). In addition, by analyzing the effect of varying the dose of challenge virus employed in the SNT $\left(10^{2}\right.$ TCID $_{50} \pm$ $0.5 \mathrm{log}$ as acceptable range for the challenge viruses) on the SN titers essentially confirmed the usefulness of a quotient of four used in classic serology as a threshold for significance (not shown). And notably, the use of cytopathogenic strains such as the strain R1935 (BVDV1a) was advantageous as it allowed for direct microscopical evaluation of the results. In field situations, however, only non-cytopathogenic strains are available and, thus, the need for fixation and immunostaining of the cells cannot be avoided.

In contrast to the test sera, the combination of BVDV1a and BDSwiss-a was not able to differentiate between BVDV and BDV as the source of infection in more than half of the field sera (55.9\%) (Table 4). In addition to the BVDV-1a subgenotype, which was never found to circulate in Switzerland, we thus included a strain of the in our country most commonly found genotype BVDV-1h $[30,37]$ into the analysis. Using these three strains as challenge viruses in the cross-SNT, we were able to diminish the rate of indeterminate samples to $18.4 \%$. As a result, we could considerably improve the former triage which was used in the laboratory that applied only two strains (BVDV-1a and BDV-1a Moredun) and that was thus unable to assign 31.0 and $66.4 \%$ of the sheep and goat sera, respectively [18]. In the case of a BVDV infection, we generally observed higher neutralisation titers against the challenge virus BVDV-1h than towards BVDV-1a, which is based on the higher antigenic homology of the field sera to a strain circulating in the Swiss cattle population. But the exclusive use of the BVDV-1h strain in combination with BDSwiss-a was not favorable as it only poorly identified BDV infections. Based on the quotients of the neutralisation titers observed (Table 3), further reduction of the number of indeterminate sera proved to be difficult. In case of acute infections in the field, direct virus isolation and partial 
sequencing of the viral genome would be required [37]. Nonetheless, the adaptation of the serological triage system to the current epidemiological situation proved to be an important prerequisite for optimal selectivity to differentiate between ruminant pestivirus infections.

A small number of samples (3.4\%) that were initially confirmed to be antibody positive by ELISA could not be confirmed in the cross-SNT (Table 4). In spite of the significant correlation between the SNT and the ELISA results (not shown), the two assays are inherently different. Thus, the epitopes important for the neutralisation assay are mainly part of the E2 envelope glycoprotein in its native conformation, whereas the "in-house" ELISA detects primarily antibodies directed to the conserved non-structural protein NS2-3 [57, 62, 68].

The results of the cross-SNTs comprising the three challenge viruses BVDV-1a, BVDV-1h, and BDSwiss-a, clearly demonstrated that the majority of pestivirus infections in cattle discovered 4 to 7 years after the start of the eradication can be ascribed to BVDV (71.5\%), whereas only $6.7 \%$ were caused by infections with BD viruses. Nevertheless, it has to be considered that at least some of the indeterminate sera (18.4\%) might also have BDV as source of infection. The BDV seroprevalence within the pestivirus-antibody positive animals slightly increased between 2012 and 2014 from 4.2 to $8.1 \%$ (not shown), whereas the overall seroprevalence in the Swiss cattle population continuously decreases [69]. These results point to a potential interference by small ruminants, in particular sheep, with the eradication of BVDV from cattle. Interestingly, small ruminants were kept - according to the entries in the animal movement database - on all case farms and on the majority of farms where BDV infections were detected by serology, with sheep being more prominent than goats. Notably, sheep flocks with more than 100 animals were exclusively found within the case farms. The highest portion of BDVspecific sera $(n=36 ; 34.6 \%)$ as well as the highest BDV seroprevalence (19\% of all seropositive samples) were obtained from Central Switzerland (Fig. 3) while the number of animals and of samples in this region are within average of all greater areas of Switzerland (Fig. 1).

By means of a logistic regression model to determine the influence of potential risk factors for an infection with BDV, we provided evidence for the impact of small ruminants. Common indoor housing of sheep and cattle was identified as the risk factor with the highest odds ratio in the final model $(\mathrm{OR}=167.23)$. Further variables with significant but smaller influence were the purchase of cattle on the level of the farm (purchase within the last 12 month $)(\mathrm{OR}=9.57)$ and on the level of the individual animal $(\mathrm{OR}=4.16)$. As the sample size of seropositive farms was limited, the power of the study was not sufficient to identify risk factors with weak association. Nonetheless, the final model confirms previous reports that pointed to the relevance of common housing of sheep and cattle as a main risk factor $[19,23,44,70]$. In particular, sheep persistently infected with BDV pose a considerable risk when housed together with BVDV-free livestock. In the course of a BVD eradication scheme, the importance of interspecies transmission might increase with the continuous decrease in antibody seroprevalence in cattle and their ensuing increase in susceptibility to (re-)infection with pestiviruses [19].

\section{Conclusion}

Collectively, our study proposes that farmers with common housing of cattle and sheep should be aware of interspecies virus transmission, especially during lambing, where a high infection pressure exists [71]. In situations where contact between cattle and sheep cannot be avoided or minimized, surveillance of pestiviruses in sheep might be considered [46]. The Swiss eradication program encompasses only bovines, but not sheep and goats. Thus, the mean BDV seroprevalence in pestivirus-antibody positive cattle of at least $6.7 \%$ with an increasing trend between 2012 and 2014 indicates that the serological surveillance by ELISA, which does not differentiate BVDV from BDV infections, might be critical. Even though discrimination by cross-SNT as described in this study is laborious, it adds to classical epidemiological investigations and allows the identification of possible sources of infection, which is of particular importance in the late phase of an eradication program [37, 48]. In summary, we determined for the first time the prevalence of BDV in pestivirus-positive cattle in Switzerland, and we provide strong evidence that common housing of cattle and sheep is the most significant risk factor for the interspecies transmission of BD virus from small ruminants to cattle.

\section{Additional files}

Additional file 1: Antibody titer of 10 sera against homologous and heterologous BDV and BVDV isolates. Cross-neutralisation titers of 10 sera against five, four, and one BVDV-I, BDV, and BVDV-II strain, respectively. (DOCX $19 \mathrm{~kb}$ )

Additional file 2: Categorical risk factors with significant differences. Categorical risk factors with significant differences between case (BDV-seropositive) and control (seronegative) farms (Additional file 2: Table S2a) and, on the animal level, between case (BDV-seropositive) and control (seronegative) farms (Additional file 2 Table S2b). (DOCX 23 kb)

Additional file 3: Continuous risk factors with significant differences between case (BDV-seropositive) and control (seronegative) farms. Within the continuous variables, differences between the number of cattle, sheep, goats, and loss of lambs between the case and control groups. (DOCX $21 \mathrm{~kb}$ )

\section{Abbreviations}

Ab: Antibody; AEC: 3-amino-9-ethylcarbazole; BDV: Border disease virus; BT cells: Bovine turbinate cells; BVDV: Bovine virus diarrhea virus; Cl: Confidence 
interval; cp: Cytopathogenic; CSFV: Classical swine fever virus; ELISA: Enzyme-linked immunosorbent assay; E-MEM: Earle's minimal essential medium; FCS: Fetal calf serum; moi: Multiplicity of infection; n.d: Not done; ncp: Non-cytopathogenic; $\mathrm{N}^{\text {pro: }}$ N-terminal protease; OIE: Office International des Epizooties (World Organisation for Animal Health); OR: Odds ratio; PBS: Phosphate buffered saline; PBS-T: PBS with 5\% Tween-20; PI: Persistently infected; SNT: Serum neutralisation test; $\mathrm{TCID}_{50}$ : Tissue culture infectious dose 50; UTR: Untranslated region

\section{Acknowledgements}

Special thanks go to Lupe Camina and Antoinette Golomingi for the preparation of the bovine turbinate cell suspension, to Claudia Bachofen for advice to compile the questionnaire and the help in finding appropriate challenge virus strains and corresponding sera, to Georg Wolf for providing the a-BVDV-2 serum, and to Peter Nettleton and Julia Ridpath for providing BDV-1a and BVDV-2 isolates, respectively. The support by Elena Di Labio and Patrick Schaller of the Federal Food Safety and Veterinary Office in providing data on the Swiss BVD eradication program and in helping to establish the list of potential control farms, and by the persons in charge of BVD of the Cantonal Veterinary Services and the Veterinary Service of the Principality of Liechtenstein, and the assigned (official) veterinarians in the collection of data on the case and control farms is highly appreciated. Last but not least, we thank Eveline Kindler for critically reading the manuscript.

\section{Funding}

This research was supported by the Federal Food Safety and Veterinary Office (grant 1.14.09 to RGZ, MS and VK).

\section{Availability of data and materials}

The datasets during and/or analyzed during the current study are available from the corresponding author on reasonable request.

\section{Authors' contributions}

RGZ and MS designed the study; VK with the aid of LN performed the experiments; GSR helped to design the questionnaire and to perform statistical analyses; VK, RGZ, and MS analyzed the data and wrote the paper. All authors critically read the manuscript and approved the final version.

\section{Competing interests}

The authors declare that they have no competing interests.

\section{Consent for publication}

Not applicable.

\section{Ethics approval and consent to participate}

Not applicable.

\section{Author details}

${ }^{1}$ Institute of Virology and Immunology, Federal Food Safety and Veterinary Office (FSVO) and Vetsuisse Faculty, University of Bern, Laenggass-Strasse 122, POB, CH-3001 Bern, Switzerland. ${ }^{2}$ Veterinary Public Health Institute, Vetsuisse Faculty, University of Bern, Schwarzenburgstrasse 155, CH-3097 Liebefeld, Switzerland.

Received: 28 July 2016 Accepted: 17 December 2016

\section{Published online: 13 January 2017}

\section{References}

1. Liu L, Xia H, Wahlberg N, Belák S, Baule C. Phylogeny, classification and evolutionary insights into pestiviruses. Virology. 2009;385:351-7.

2. Becher P, Thiel H-J. Genus Pestivirus (Flaviviridae). In: Tidona CA, Darai G, editors. The springer index of viruses. 2nd ed. Heidelberg: Springer Verlag; 2011. p. 483-8.

3. Ridpath JF. Emerging pestiviruses infecting domestic and wildlife hosts. Anim Health Res Rev. 2015;16:55-9.

4. Hause BM, Collin EA, Peddireddi L, Yuan FF, Chen ZH, Hesse RA, et al. Discovery of a novel putative atypical porcine pestivirus in pigs in the USA. J Gen Virol. 2015;96:2994-8.

5. Arruda BL, Arruda PH, Magstadt DR, Schwartz KJ, Dohlman T, Schleining JA, et al. Identification of a divergent lineage porcine pestivirus in nursing piglets with congenital tremors and reproduction of disease following experimental inoculation. PLOS ONE. 2016;11:e0150104.
6. Nettleton PF, Entrican G. Ruminant pestiviruses. Br Vet J. 1995;151:615-42.

7. Houe $\mathrm{H}$. Epidemiological features and economical importance of bovine virus diarrhoea virus (BVDV) infections. Vet Microbiol. 1999;64:89-107.

8. Moennig V, Houe H, Lindberg A. BVD control in Europe: current status and perspectives. Anim Health Res Rev. 2005;6:63-74.

9. Müller-Doblies D, Arquint A, Schaller P, Heegaard PMH, Hilbe M, Albini S, et al. Innate immune responses of calves during transient infection with a noncytopathic strain of bovine viral diarrhea virus. Clin Diagn Lab Immunol. 2004;11:302-12.

10. Brodersen BW. Bovine viral diarrhea virus infections: manifestations of infection and recent advances in understanding pathogenesis and control. Vet Pathol. 2014;51:453-64.

11. Peterhans E, Schweizer M. BVDV: a pestivirus inducing tolerance of the innate immune response. Biologicals. 2013;41:39-51.

12. Lanyon SR, Hill Fl, Reichel MP, Brownlie J. Bovine viral diarrhoea: pathogenesis and diagnosis. Vet J. 2014;199:201-9.

13. Schweizer M, Peterhans E. Pestiviruses. Annu Rev Anim Biosci. 2014;2:141-63.

14. Nettleton PF, Gilray JA, Russo P, Dlissi E. Border disease of sheep and goats. Vet Res. 1998;29:327-40.

15. García-Pérez AL, Minguijon E, Estevez L, Barandika JF, Aduriz G, Juste RA, et al. Clinical and laboratorial findings in pregnant ewes and their progeny infected with border disease virus (BDV-4 genotype). Res Vet Sci. 2009;86:345-52.

16. Hilbe M, Camenisch U, Braun U, Peterhans E, Stalder HP, Zlinszky K, et al. Mucosal lesions in a sheep infected with the Border Disease Virus (BDV). Schweiz Arch Tierheilkd. 2009;151:391-6.

17. Oğuzoğlu TC. A review of border disease virus infection in ruminants: molecular characterization, pathogenesis, diagnosis and control. Animal Health Product Hyg. 2012;1:1-9.

18. Danuser R, Vogt HR, Kaufmann T, Peterhans E, Zanoni R. Seroprevalence and characterization of pestivirus infections in small ruminants and new world camelids in Switzerland. Schweiz Arch Tierheilkd. 2009;151:109-17.

19. Krametter-Froetscher R, Duenser M, Preyler B, Theiner A, Benetka V, Moestl $K$, et al. Pestivirus infection in sheep and goats in West Austria. Vet J. 2010;186:342-6.

20. Passler T, Walz PH. Bovine viral diarrhea virus infections in heterologous species. Anim Health Res Rev. 2010;11:191-205.

21. Braun U, Hilbe M, Ehrensperger F, Salis F, Alther P, Strasser M, et al. Border disease in a flock of sheep. Schweiz Arch Tierheilkd. 2002;144:419-26.

22. Schaller P, Vogt HR, Strasser M, Nettleton PF, Peterhans E, Zanoni R. Seroprevalence of maedi-visna and border disease in Switzerland. Schweiz Arch Tierheilkd. 2000;142:145-53.

23. Braun U, Bachofen C, Schenk B, Hässig M, Peterhans E. Investigation of border disease and bovine virus diarrhoea in sheep from 76 mixed cattle and sheep farms in eastern Switzerland. Schweiz Arch Tierheilkd. 2013;155:293-8.

24. Becher P, Avalos-Ramirez R, Orlich M, Rosales SC, König M, Schweizer M, et al. Genetic and antigenic characterization of novel pestivirus genotypes: implications for classification. Virology. 2003;311:96-104.

25. Thabti F, Letellier C, Hammami S, Pepin M, Ribiere M, Mesplede A, et al. Detection of a novel border disease virus subgroup in Tunisian sheep. Arch Virol. 2005;150:215-29.

26. Ridpath JF, Fulton RW, Kirkland PD, Neill JD. Prevalence and antigenic differences observed between bovine viral diarrhea virus subgenotypes isolated from cattle in Australia and feedlots in the southwestern United States. J Vet Diagn Invest. 2010;22:184-91.

27. Nagai M, Ito T, Sugita S, Genno A, Takeuchi K, Ozawa T, et al. Genomic and serological diversity of bovine viral diarrhea virus in Japan. Arch Virol. 2001;146:685-96.

28. Couvreur B, Letellier C, Collard A, Quenon P, Dehan P, Hamers C, et al. Genetic and antigenic variability in bovine viral diarrhea virus (BVDV) isolates from Belgium. Virus Res. 2002;85:17-28.

29. Pizarro-Lucero J, Celedón MO, Aguilera M, De Calisto A. Molecular characterization of pestiviruses isolated from bovines in Chile. Vet Microbiol. 2006;115:208-17.

30. Bachofen C, Stalder HP, Braun U, Hilbe M, Ehrensperger F, Peterhans E. Co-existence of genetically and antigenically diverse bovine viral diarrhoea viruses in an endemic situation. Vet Microbiol. 2008;131:93-102.

31. Nagai M, Hayashi M, Itou M, Fukutomi T, Akashi $H$, Kida $H$, et al. Identification of new genetic subtypes of bovine viral diarrhea virus genotype 1 isolated in Japan. Virus Genes. 2008;36:135-9. 
32. Minami F, Nagai M, Ito M, Matsuda $T$, Takai $H$, Jinkawa $Y$, et al. Reactivity and prevalence of neutralizing antibodies against Japanese strains of bovine viral diarrhea virus subgenotypes. Comp Immunol Microbiol Infect Dis. 2011;34:35-9.

33. Alpay $G$, Yeşilbağ K. Serological relationships among subgroups in bovine viral diarrhea virus genotype 1 (BVDV-1). Vet Microbiol. 2015;175:1-6.

34. Giammarioli M, Ceglie L, Rossi E, Bazzucchi M, Casciari C, Petrini S, et al. Increased genetic diversity of BVDV-1: recent findings and implications thereof. Virus Genes. 2015;50:147-51.

35. Decaro N, Lucente MS, Lanave G, Gargano P, Larocca V, Losurdo M et al. Evidence for circulation of bovine viral diarrhoea virus type $2 \mathrm{C}$ in ruminants in Southern Italy. Transbound Emerg Dis. 2016. In press. doi:10.1111/tbed.12592.

36. Stalder HP, Meier P, Pfaffen G, Wageck-Canal C, Rüfenacht J, Schaller P, et al, Genetic heterogeneity of pestiviruses of ruminants in Switzerland. Prev Vet Med. 2005;72:37-41.

37. Stalder HP, Hug C, Zanoni R, Vogt HR, Peterhans E, Schweizer M, et al. A nationwide database linking information on the hosts with sequence data of their virus strains: a useful tool for the eradication of bovine viral diarrhea (BVD) in Switzerland. Virus Res. 2016;218:49-56.

38. Dubois E, Russo P, Prigent M, Thiéry R. Genetic characterization of ovine pestiviruses isolated in France, between 1985 and 2006. Vet Microbiol. 2008;130:69-79.

39. Giammarioli M, La Rocca SA, Steinbach F, Casciari C, De Mia GM. Genetic and antigenic typing of border disease virus (BDV) isolates from Italy reveals the existence of a novel BDV group. Vet Microbiol. 2011;147:231-6.

40. Peterhans E, Bachofen C, Stalder HP, Schweizer M. Cytopathic bovine viral diarrhea viruses (BVDV): emerging pestiviruses doomed to extinction. Vet Res. 2010;41:44.

41. Braun U, Hilbe M, Janett F, Hässig M, Zanoni R, Frei S, et al. Transmission of border disease virus from a persistently infected calf to seronegative heifers in early pregnancy. BMC Vet Res. 2015;11:43.

42. Peletto S, Caruso C, Cerutti F, Modesto P, Zoppi S, Dondo A, et al. A new genotype of border disease virus with implications for molecular diagnostics. Arch Virol. 2016;161:471-7.

43. Bachofen C, Vogt HR, Stalder H, Mathys T, Zanoni R, Hilbe M, et al. Persistent infections after natural transmission of bovine viral diarrhoea virus from cattle to goats and among goats. Vet Res. 2013;44:32.

44. Braun U, Reichle SF, Reichert C, Hässig M, Stalder HP, Bachofen C, et al. Sheep persistently infected with Border disease readily transmit virus to calves seronegative to BVD virus. Vet Microbiol. 2014;168:98-104.

45. Cranwell MP, Otter A, Errington J, Hogg RA, Wakeley P, Sandvik T. Detection of border disease virus in cattle. Vet Rec. 2007;161:211-2.

46. Strong R, La Rocca SA, Ibata G, Sandvik T. Antigenic and genetic characterisation of border disease viruses isolated from UK cattle. Vet Microbiol. 2010;141:208-15

47. Hornberg A, Fernández SR, Vogl C, Vilček Š, Matt M, Fink M, et al. Genetic diversity of pestivirus isolates in cattle from Western Austria. Vet Microbiol. 2009;135:205-13.

48. Krametter-Froetscher R, Benetka V, Rasser K, Tockner F, Moesslacher G, Moestl K, et al. BVDV control program in Austria - is a monitoring of the BDV status in sheep in Austria necessary? Vet Med (Praha). 2009:54:517-24.

49. Schirrmeier $\mathrm{H}$, Strebelow G, Tavella A, Stifter E: Border disease virus infection in cattle - epidemiological and diagnostic impact. In: $7^{\text {th }}$ ESW Pestivirus Symposium. Uppsala (Sweden); 2008: 172.

50. McFadden AMJ, Tisdall DJ, Hill FI, Otterson P, Pulford D, Peake J, et al. The first case of a bull persistently infected with Border disease virus in New Zealand. N Z Vet J. 2012;60:290-6.

51. Braun U, Bachofen C, Büchi R, Hässig M, Peterhans E. Infection of cattle with Border disease virus by sheep on communal alpine pastures. Schweiz Arch Tierheilkd. 2013;155:123-8.

52. Greiser-Wilke I, Grummer B, Moennig V. Bovine viral diarrhoea eradication and control programmes in Europe. Biologicals. 2003;31:113-8.

53. Ståhl K, Alenius S. BVDV control and eradication in Europe - an update. Jpn J Vet Res. 2012;60:S31-9.

54. Presi P, Heim D. BVD eradication in Switzerland-a new approach. Vet Microbiol. 2010;142:137-42.

55. Bachofen C, Stalder HP, Vogt HR, Wegmüller M, Schweizer M, Zanoni R, et al. Bovine Virusdiarrhöe (BVD): von der Biologie zur Bekämpfung. Berl Munch Tierarztl Wochenschr. 2013;126:452-61.
56. Schärrer S, Widgren S, Schwermer H, Lindberg A, Vidondo B, Zinsstag J, et al. Evaluation of farm-level parameters derived from animal movements for use in risk-based surveillance programmes of cattle in Switzerland. BMC Vet Res. 2015;11:149.

57. Canal CW, Strasser M, Hertig C, Masuda A, Peterhans E. Detection of antibodies to bovine viral diarrhoea virus (BVDV) and characterization of genomes of BVDV from Brazil. Vet Microbiol. 1998;63:85-97.

58. Schwermer H, Bernet D, Presi P, Schaller P, Stern M, Heim D. Data management systems for the bovine viral diarrhoea eradication programme in Switzerland. Rev Sci Tech. 2013;32:741-50.

59. Steck F, Lazary S, Fey H, Wandeler A, Huggler C, Oppliger G, et al. Immune responsiveness in cattle fatally affected by bovine virus diarrhea-mucosal disease. Zentralb| Veterinarmed B. 1980;27:429-45.

60. Wolfmeyer A, Wolf G, Beer M, Strube W, Hehnen HR, Schmeer N, et al. Genomic (5'UTR) and serological differences among German BVDV field isolates. Arch Virol. 1997;142:2049-57.

61. Edwards $\mathrm{S}$. The diagnosis of bovine virus diarrhoea-mucosal disease in cattle. Rev Sci Tech. 1990;9:115-30.

62. Sandvik T. Laboratory diagnostic investigations for bovine viral diarrhoea virus infections in cattle. Vet Microbiol. 1999;64:123-34.

63. Kirkland PD, Lung O, Drew T. Bovine viral diarrhoea. chapter 2.4.8. In: Manual of standards for diagnostic tests and vaccines for terrestrial animals office international des epizooties (OIE). 2015. p. 690-703.

64. Presi P, Struchen R, Knight-Jones T, Scholl S, Heim D. Bovine viral diarrhea (BVD) eradication in Switzerland-experiences of the first two years. Prev Vet Med. 2011;99:112-21.

65. Liang KY, Zeger SL. Longitudinal data analysis using generalized linear models. Biometrika. 1986;73:13-22.

66. Avalos-Ramirez R, Orlich M, Thiel H-J, Becher P. Evidence for the presence of two novel pestivirus species. Virology. 2001;286:456-65.

67. Archetti I, Horsfall FL. Persistent antigenic variation of influenza A viruses after incomplete neutralization in ovo with heterologous immune serum. J Exp Med. 1950:92:441-62.

68. Bachofen C, Bollinger B, Peterhans E, Stalder HP, Schweizer M. Diagnostic gap in Bovine viral diarrhea virus serology during the periparturient period in cattle. J Vet Diagn Invest. 2013;25:655-61.

69. Di Labio E. Stand der BVD-Ausrottung in der Schweiz. In: 9 Stendaler Symposium: Tierseuchenbekämpfung, Tierschutz und Tierarzneimittel bei Rindern. Stendal: 2015.

70. Carlsson U, Belák K. Border disease virus transmitted to sheep and cattle by a persistently infected ewe: epidemiology and control. Acta Vet Scand. 1994;35:79-88.

71. Lindberg A, Stokstad M, Løken T, Alenius S, Niskanen R. Indirect transmission of bovine viral diarrhoea virus at calving and during the postparturient period. Vet Rec. 2004;154:463-7.

72. Barlow RM. Experiments in Border disease: IV. Pathological changes in ewes. J Comp Pathol. 1972;82:151-7.

73. Bolin SR, Ridpath JF. Differences in virulence between two noncytopathic bovine viral diarrhea viruses in calves. Am J Vet Res. 1992;53:2157-63.

\section{Submit your next manuscript to BioMed Central and we will help you at every step:}

- We accept pre-submission inquiries

- Our selector tool helps you to find the most relevant journal

- We provide round the clock customer support

- Convenient online submission

- Thorough peer review

- Inclusion in PubMed and all major indexing services

- Maximum visibility for your research

Submit your manuscript at www.biomedcentral.com/submit 